\title{
Boric acid as a protector against paclitaxel genotoxicity
}

\author{
Hasan Turkez ${ }^{1}$, Abdulgani Tatar ${ }^{2 凶}$, Ahmet Hacımuftuoglu³ and Ebru Ozdemir ${ }^{2}$ \\ 'Department of Biology, Faculty of Science, Ataturk University, Erzurum, Turkey; ${ }^{2}$ Department of Medical Genetics, Medical Faculty, Ataturk \\ University, Erzurum, Turkey; ${ }^{3}$ Department of Pharmacology, Medical Faculty, Ataturk University, Erzurum, Turkey
}

\begin{abstract}
Paclitaxel (PAC) is an anticancer drug used for treatments of breast, ovarian and lung cancers. However, little data is available in the literature on its potential genotoxicity on healthy human cells. On the other hand, boron deficiency and supplementation exert important biological effects in human and animal tissues. The biological effects of dietary boron are defined, but its interaction with PAC is not known for therapeutic uses. The aim of the present study was to determine whether boric acid (BA) confer a protection against PAC genotoxicity. After the application of PAC (10 or $20 \mu \mathrm{g} / \mathrm{l})$ and BA ( 2.5 or $5 \mathrm{mg} / \mathrm{l})$, the genotoxic effects were assessed by sister chromatid exchange (SCE) and micronucleus (MN) tests in human blood cultures. We also analyzed nuclear division index (NDI) in peripheral lymphocytes. Our results showed that PAC significantly $(P<0.05)$ increased the frequencies of SCEs and the formations of MNs in peripheral lymphocytes as compared to controls. PAC decreased the nuclear division index in lymphocyte cultures. Boric acid did not show cytotoxic or genotoxic effects at the concentrations tested. Furthermore, the PAC-induced increases in the genotoxicity and cytotoxicity indices were diminished by the addition of BA. The present study suggests for the first time that BA can prevent the genotoxicity of PAC on human lymphocytes.
\end{abstract}

Keywords: boric acid, paclitaxel, sister chromatid exchange, micronucleus, nuclear division index

Received: 14 November, 2009; revised: 04 January, 2010; accepted: 13 January, 2010; available on-line: 19 March, 2010

\section{INTRODUCTION}

Paclitaxel (PAC), an anticancer drug, is used for the treatments of breast, ovarian, lung, head and neck cancers (Von Hoff, 1997; Rowinsky, 1997). However, this drug is known to cause adverse effects in different organs such as heart and brain (Lachkar et al., 2006). Therefore, numerous investigations have been performed to find protective agents minimizing the adverse effects of PAC (Della Torre, 1999; Kanat et al., 2003; Openshaw et al., 2004; Chentanez et al., 2009). The generation of reactive oxygen species (ROS) increases in cells after PAC treatment. The increase in ROS production can be suppressed by antioxidants (Wang et al., 2004). Some studies showed that boron compounds have nutritional benefits such as increased vitamin $\mathrm{D}$ biosynthesis and induction of hematopoiesis, and the ability to strengthen the tissue antioxidant defenses in animals and humans (Hunt \& Idso, 1999; Pawa \& Ali, 2006). In addition, it has been reported that boric acid (BA) is a non-genotoxic agent increasing the antioxidant capacity of cultured human blood cells (Turkez et al., 2007; Turkez, 2008). To our best knowledge, there has been no report about the role of BA on PAC-treated cultures. In this study, we investigated the protective effect of BA in human lymphocyte cell cultures treated with PAC. The sister chromatid exchange (SCE) and micronucleus (MN) tests, considered to be sensitive methods for detecting DNA damage (Wu $\& \mathrm{Wu}, 1995)$, were used to assess the genetic damage.

\section{MATERIAL AND METHODS}

Cell cultures. Whole blood samples were collected from two healthy non-smoker donors with no history of exposure to any genotoxic agent. Cultures were set up according to the protocol described by Evans and O'Riordan (1975) with a slight modification. The peripheral blood lymphocytes $(0.5 \mathrm{ml})$ were cultured in $5 \mathrm{ml}$ of culture medium (Chromosome Medium B, Biochrom ${ }^{\circledR}$ ) with phytohemagglutinin. PAC (10 or $20 \mu \mathrm{g} / \mathrm{l}$ ) (taxol, Bristol-Myers Squibb) and BA (2.5 or $5 \mathrm{mg} / \mathrm{l}$ ) (Sigma) were added alone or together to the cultures except control group just before incubation.

SCE (sister chromatid exchange) test. To determine the frequency of SCE in the lymphocytes, BrdU (5-bromo-2'-deoxyuridine, Sigma, MO, USA) was added to each culture $\left(10^{-4} \mathrm{M}\right.$ final concentration) and the cultures were incubated in complete darkness for $72 \mathrm{~h}$ at $37^{\circ} \mathrm{C}$. Colchicine $(0.5 \mu \mathrm{g} / \mathrm{ml}$, Sigma $)$ was added to each culture during the last $2 \mathrm{~h}$ of the incubation to block the cells in metaphase. After the incubation, the cultures were harvested by a procedure including hypotonic treatment $(0.075 \mathrm{M} \mathrm{KCl})$ for $25 \mathrm{~min}$ followed by three repetitive cycles of fixation in methanol/acetic acid solution $(3: 1, \mathrm{v} / \mathrm{v})$. The cell suspension was dropped onto cold microscopic slides. The slides were dried at room temperature and complete darkness for three days. They were differentially stained for inspection of the SCE rate according to the fluorescence plus Giemsa (FPG) procedure (Rooney \& Czepulkowski, 1986). For each treatment condition, 20 well-spread second division metaphases containing 46 chromosomes in each cell were scored by using an Olympus BH-2 microscope (Olympus Corp., Tokyo, Japan) and the values obtained were calculated as SCEs per cell.

e-mail: agtatar@gmail.com

Abbreviations: BA, boric acid; BrdU, 5-bromo-2'-deoxyuridine; FPG, fluorescence plus Giemsa; MN, micronucleus; NDI, nuclear division index; PAC, paclitaxel; SCE, sister chromatid exchange. 
Micronucleus (MN) test and Nuclear Division In$\operatorname{dex}($ NDI) analysis. In order to detect the number of micronucleated lymphocytes, cytochalasin B $(4.5 \mu \mathrm{g} / \mathrm{ml}$, Sigma) were added to the cultures at 44th hour. At the end of the $72 \mathrm{~h}$ incubation period, the lymphocytes was treated with $0.075 \mathrm{M} \mathrm{KCl}$ for $8 \mathrm{~min}$ at $37^{\circ} \mathrm{C}$. After three fixation cycles with methanol/acetic acid (396:1, v/v), cell suspension was dropped onto cold slides. The slides were air-dried at room temp. and then stained with 5\% Giemsa for $15 \mathrm{~min}$. All slides were coded before scoring. The criteria for scoring micronuclei were as described by Fenech (1993). At least 2000 binucleated lymphocytes per concentration were examined for the presence of one, two or more micronuclei.

For cell cycle analysis, 400 cells per treatment group were scored for the presence of one, two or more than two nuclei and the nuclear division index (NDI) was calculated as follows:

$\mathrm{NDI}=[1 \mathrm{~N}+(2 \times 2 \mathrm{~N})+(4 \times>2 \mathrm{~N})] / \mathrm{C}$

where $1 \mathrm{~N}$ is number of cells with one nucleus, $2 \mathrm{~N}$ with two nuclei, and $>2 \mathrm{~N}$ - with more than two nuclei, $\mathrm{C}$ - number of cells examined (Konopacka \& Rogolinski, 2004).

Statistical analysis. The statistical analysis of experimental values in the SCE and MN tests was performed by Student's $t$-test and using the S.P.S.S. 12.0 software. Statistical decisions were made with a significance level of 0.05 .

\section{RESULTS}

Our results showed that BA (at either dose) did not alter SCE and MN frequencies in human lymphocytes. PAC at 10 and $20 \mu \mathrm{g} / \mathrm{l}$ significantly increased the SCE rates and $\mathrm{MN}$ formation in lymphocytes as compared with controls (Figs. 1 and 2). When the two agents were used, BA reduced the number of PAC-induced SCE and $\mathrm{MN}$ formation but it did not completely revert the PACcaused SCE and MN induction.

PAC at $20 \mu \mathrm{g} / 1$ also reduced the NDI in human lymphocytes in vitro (Fig. 3). Addition of BA to the cultures brought back the NDI rates to the control value.

\section{DISCUSSION}

Our results clearly indicated the PAC induced genotoxic and cytotoxic damage in human lymphocytes. Similarly to our findings, a few reports indicated in vitro paclitaxel genotoxicity. Preisler et al. (1999) investigated the genotoxic effects of a combination of PAC and radiation in four mammalian cell lines including L5178Y, V79, HeLa and breast cancer cell line MCF-7 by the MN assay. They showed that the MN frequencies in combined treatments were different from a presumed additive effect of the single treatments. PAC was found to be a strong in vitro aneugenic drug in human normal cells at therapeutic doses (Digue et al., 1999). In another report, PAC significantly increased the micronucleated rates in a concentration-dependant manner in healthy human lymphocytes (Digue et al., 2002). In contrast to those in vitro results, Cunha et al. (2001) reported that paclitaxel was non-genotoxic in Drosophila wing somatic mutation and recombination test (SMART). However, PAC appeared as cytotoxic clastogene in mouse lymphoma cells by using comet and apoptotic assays (Lee et al., 2003). And

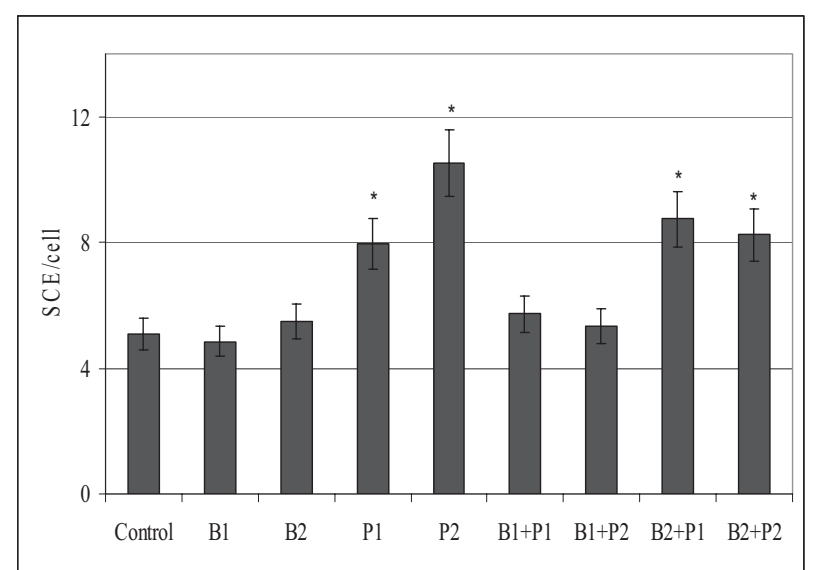

Figure 1. SCE frequencies in cultured human lymphocytes treated with $P A C$ and $B A$

$\mathrm{B} 1=2.5 \mathrm{mg} / \mathrm{l} \mathrm{BA} ; \mathrm{B} 2=5 \mathrm{mg} / \mathrm{l} \mathrm{BA} ; \mathrm{P} 1=10 \mu \mathrm{g} / \mathrm{l} P A C ; \mathrm{P} 2=20 \mu \mathrm{g} / \mathrm{l}$ $\mathrm{PAC} ;{ }^{*}$ represents statistically significant differences from control group $(P<0.05)$. Values are means \pm standard deviation.

the cytotoxic activity of PAC was suggested partially due to its ability to induce apoptosis via activation of cell cycle dependent kinases leading to activation of caspases (Moos \& Fitzpatrick, 1998) and then further to DNA fragmentation (Ellinger-Ziegelbauer et al., 2009). This is in line with previously published data and PAC was found to be genotoxic in normal non-human primate bone marrow cells (Rao et al., 2005). We also found a significant decrease in the rate of NDI after the treatment with high PAC dose, which could be due to its anti-proliferative action in vitro (Axel et al., 1997). As a matter of fact, PAC has been shown to inhibit cell cycle progression and to induce cell cycle arrest prior to the induction of apoptosis in cancer cells by binding to microtubules (Aoudjit \& Vuori, 2001).

The present study also demonstrated that the reduction of PAC induced SCE and MN formation was caused by the protective effect of BA. Earlier studies showed that BA did not lead to DNA damage in lymphocytes (Turkez et al., 2007). Moreover, this compound significantly decreased genotoxic effects of some agents such as titanium and vanadium (Turkez, 2008; Geyikoglu \& Turkez, 2008). This protective mechanism of $\mathrm{BA}$ is unclear but it can be due to its ability to strengthen the

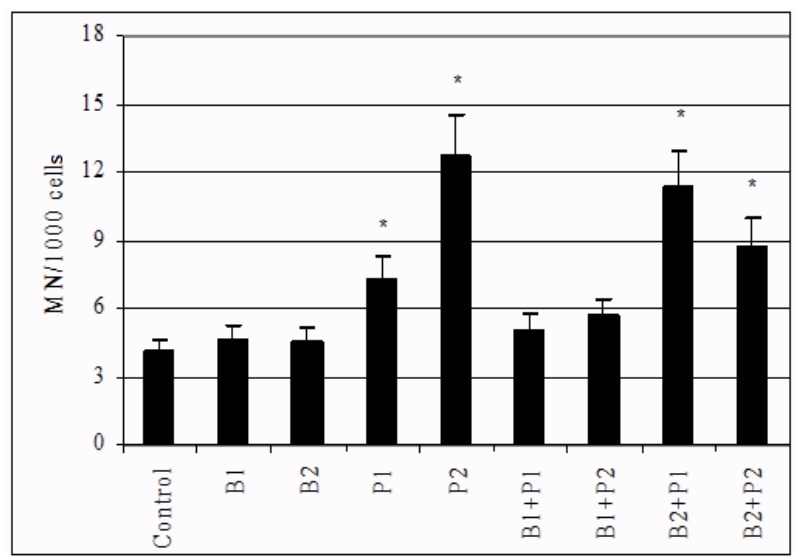

Figure 2. Rates of $M N$ in cultured human lymphocytes treated with PAC and BA

Abbreviations are as in Fig. 1. 


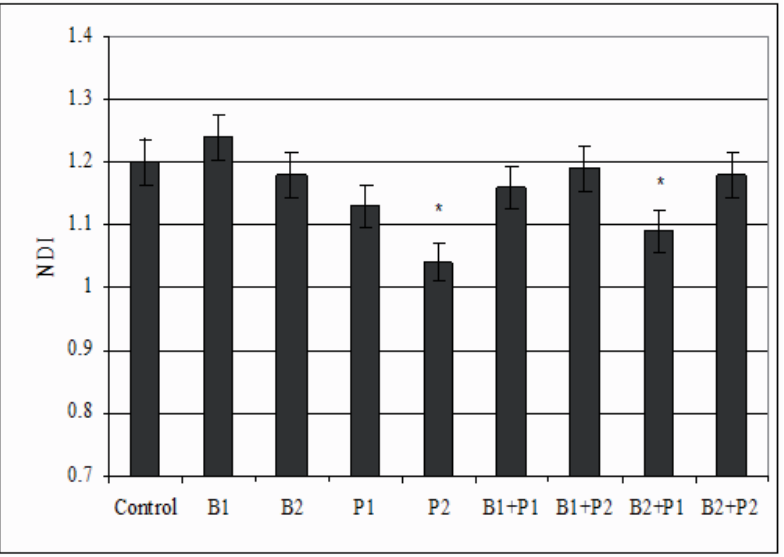

Figure 3. Rates of NDI in cultured human lymphocytes treated with $P A C$ and $B A$

Abbreviations are as in Fig. 1.

tissue antioxidant capacity and defense against free oxygen radicals. In line with that, a study by Ramanathan et al. (2005) indicated that reactive oxygen and nitrogen species were involved in PAC cytotoxicity. Thus, BA could modulate the PAC-induced genetic and cytotoxic damage by preventing free radical generation or by stimulating components of the antioxidant defense system. In addition, our results revealed that $2.5 \mathrm{mg} / 1$ of $\mathrm{BA}$ had a stronger protective effect than $5 \mathrm{mg} / \mathrm{l}$. The reason could be that the higher dose $(5 \mathrm{mg} / \mathrm{l})$ used was beyond the physiological limits. In fact, normal value of $\mathrm{BA}$ in the blood has been reported as $3 \mathrm{mg} / 1$ (EVM, 2002, Expert Group on Vitamins and Minerals. Revised review of boron. EVM/99/23/P.REVISEDAUG2002). $\mathrm{BA}$ also loses its protective action and becomes toxic at doses above physiological limits (Turkez et al., 2007).

In conclusion, our results clearly indicated that boron (as BA) supplementation to lymphocyte cultures ameliorated the PAC- induced DNA damage. BA could play a similar role in cancer patients after chemotherapy. However, specific protective agents for chemotherapyinduced adverse effects after PAC or other anti-cancer drugs treatment should not show any interference with the antitumor activity of the drugs (Pisano et al., 2003), and the in vivo interactions of $\mathrm{BA}$ and $\mathrm{PAC}$ are still unknown. At this point, further in vivo investigations are necessary to justify daily intake of boron to minimize adverse effects of anti-cancer drugs.

\section{REFERENCES}

Aoudjit F, Vuori K (2001). Integrin signaling inhibits paclitaxel-induced apoptosis in breast cancer cells. Oncogene 20: 4995-5004.

Axel DI, Kunert W, Göggelmann C, Oberhoff M, Herdeg C, Küttner A, Wild DH, Brehm BR, Riessen R, Köveker G, Karsch KR (1997) Paclitaxel inhibits arterial smooth muscle cell proliferation and migration in vitro and in vivo using local drug delivery. Circulation 96: 636-645.

Chentanez V, Thanomsridejchai N, Duangmardphon N, Agthong S, Kaewsema A, Huanmanop T, Maneesri S (2009) Ganglioside GM1 (porcine) ameliorates paclitaxel-induced neuropathy in rats. J Med Assoc Thai 92: 50-57.

Cunha KS, Reguly ML, Graf U, de Andrade HH (2001) Taxanes: the genetic toxicity of paclitaxel and docetaxel in somatic cells of Drosophila melanogaster. Mutagenesis 16: 79-84.

Della Torre P, Imondi AR, Bernardi C, Podesta A, Moneta D, Riflettuto M, Mazue G (1999) Cardioprotection by dexrazoxane in rats treated with doxorubicin and paclitaxel. Cancer Chemother Pharmacol 44: $138-142$.
Digue L, Orsiere T, De Meo M, Mattei MG, Depetris D, Duffaud F, Favre R, Botta A (1999) Evaluation of the genotoxic activity of paclitaxel by the in vitro micronucleus test in combination with fluorescent in situ hybridization of a DNA centromeric probe and the alkaline single cell gel electrophoresis technique (comet assay) in human T-lymphocytes. Environ Mol Mutagen 34: 269-278.

Digue L, Orsiere T, Baciuchka-Palmaro M, Duffaud F, Pompili J, Favre R, Botta A (2002) Interest of studying the in vitro genotoxicity of an antineoplastic drug on healthy human cells: paclitaxel example. Bull Cancer 89: 887-892.

Ellinger-Ziegelbauer H, Fostel JM, Aruga C, Bauer D, Boitier E, Deng S, Dickinson D, Le Fevre AC, Fornace AJ Jr, Grenet O, Gu Y, Hoflack JC, Shiiyama M, Smith R, Snyder RD, Spire C, Tanaka G, Aubrecht J (2009) Characterization and interlaboratory comparison of a gene expression signature for differentiating genotoxic mechanisms. Toxicol Sci 110: 341-352.

Evans HJ, O'Riordan ML (1975) Human peripheral blood lymphocytes for the analysis of chromosome aberrations in mutagen tests. Mutat Res 31: 135-148.

Fenech M (1993) The cytokinesis-block micronucleus technique: a detailed description of the method and its application to genotoxicity studies in human populations. Mutat Res 285: 35-44.

Geyikoglu F, Turkez H (2008) Boron compounds reduce vanadium tetraoxide genotoxicity in human lymphocytes. Environ Toxicol Pharmacol 26: 342-347.

Hunt CD, Idso JP (1999) Dietary boron as a physiological regulator of the normal inflammatory response: a review and current research progress. I Trace Elem Exp Med 12: 221-233.

Kanat O, Evrensel T, Baran I, Coskun H, Zarifoglu M, Turan OF, Kurt E, Demiray M, Gonullu G, Manavoglu O (2003) Protective effect of amifostine against toxicity of paclitaxel and carboplatin in non-small cell lung cancer: a single center randomized study. Med Oncol 20: 237-245.

Konopacka M, Rogolinski J (2004) Thiamine prevents X-ray induction of genetic changes in human lymphocytes in vitro. Acta Biochim Pol 51: 839-843.

Lachkar S, Bota S, Nouvet G, Thiberville L (2006) Acute encephalopathy after infusion of paclitaxel. Rev Mal Respir 23: 73-77.

Lee M, Kwon J, Chung MK (2003) Enhanced prediction of potential rodent carcinogenicity by utilizing comet assay and apoptotic assay in combination. Mutat Res 541: 9-19.

Moos PJ, Fitzpatrick FA (1998) Taxanes propagate apoptosis via two cell populations with distinctive cytological and molecular traits. Cell Growth Differ 9: 687-697.

Openshaw H, Beamon K, Synold TW, Longmate J, Slatkin NE, Doroshow JH, Forman S, Margolin K, Morgan R, Shibata S, Somlo G (2004) Neurophysiological study of peripheral neuropathy after high-dose paclitaxel: lack of neuroprotective effect of amifostine. Clin Cancer Res 10: 461-467.

Pawa S, Ali S (2006) Boron ameliorates fulminant hepatic failure by counteracting the changes associated with the oxidative stress. Chem Biol Interact 160: 89-98.

Pisano C, Pratesi G, Laccabue D, Zunino F, Lo Giudice P, Bellucci A, Pacifici L, Camerini B, Vesci L, Castorina M, Cicuzza S, Tredici G, Marmiroli P, Nicolini G, Galbiati S, Calvani M, Carminati P, Cavaletti G (2003) Paclitaxel and cisplatin-induced neurotoxicity: a protective role of acetyl-L-carnitine. Clin Cancer Res 9: 5756-5767.

Preisler VK, Wück D, Stopper H (1999) Combination of paclitaxel and radiation: genotoxicity in vitro in four mammalian cell lines. Cancer Lett 145: 29-33.

Ramanathan B, Jan KY, Chen CH, Hour TC, Yu HJ, Pu YS (2005) Resistance to paclitaxel is proportional to cellular total antioxidant capacity. Cancer Res 65: 8455-8460.

Rao VK, Knutsen T, Ried T, Wangsa D, Flynn BM, Langham G, Egorin MJ, Cole D, Balis F, Steinberg SM, Bates S, Fojo T (2005) The extent of chromosomal aberrations induced by chemotherapy in non-human primates depends on the schedule of administration. Mutat Res 583: 105-119.

Rooney DE, Czepulkowski BH (1986) Human Cytogenetics: A Practical Approach. IRL Press Ltd., Oxford.

Rowinsky EK (1997) The development and clinical utility of the taxane class of antimicrotubule chemotherapy agents. Annu Rev Med 48: 353-374.

Turkez H (2008) Effects of boric acid and borax on titanium dioxide genotoxicity. J Appl Toxicol 28: 658-664.

Türkez H, Geyikoğlu F, Tatar A, Keleş S, Ozkan A (2007) Effects of some boron compounds on peripheral human blood. Z Naturforsch (C) 62: 889-896.

Von Hoff DD (1997) The taxoids: same roots, different drugs. Semin Oncol 2: 3-10.

Wang YF, Chen CY, Chung SF, Chiou YH, Lo HR (2004) Involvement of oxidative stress and caspase activation in paclitaxel-induced apoptosis of primary effusion lymphoma cells. Cancer Chemother Pharmacol 54: 322-330.

Wu DQ, Wu Y (1995) Micronucleus and sister chromatid exchange frequency in endemic fluorosis. Fluoride 28: 125-127. 